\title{
Debt of Family Medicine Residents Continues to Grow
}

\author{
Julie P. Phillips, MD, MPH, Zachary J. Morgan, MS, Andrew W. Bazemore, MD, MPH, \\ and Lars E. Peterson, $M D, P h D$
}

The proportion of family medicine residents with $\geq \$ 250,000$ in self-reported educational debt rose from $26 \%$ in $2014 \%$ to $47 \%$ in 2019 . Such a rapid rise in high indebtedness is concerning, given known associations with resident distress. Previous research has also shown that highly indebted residents are less likely to choose academics, geriatrics, and service-oriented career paths. ( $\mathrm{J}$ Am Board Fam Med 2021;34:663-664.)

Keywords: Career Choice, Family Medicine, Medical Education, Primary Health Care, Students, Workforce

Educational debt is a growing concern in the United States. In 2019, the median indebted graduate of an allopathic US medical school carried $\$ 200,000$ in educational debt, ${ }^{1}$ the average osteopathic student, \$256,562. ${ }^{2}$ Among medical students, high debt has been correlated with markers of distress, academic failure, ${ }^{3}$ and a higher likelihood of selecting higher-income specialty careers. ${ }^{4}$

Although less research has been conducted on residents, studies have demonstrated a similar pattern: residents with more debt perform less well academically, experience more distress, and make different longterm career decisions. ${ }^{5-7}$ Specifically, highly indebted family medicine residents are less likely to choose academics, geriatrics, and service-oriented careers. ${ }^{5}$ In 2014, over $50 \%$ of graduating family medicine (FM) residents reported student debt over $\$ 150,000 .{ }^{8}$ The purpose of this study was to examine trends in graduating FM residents' debt between 2014 and 2019.

This article was externally peer reviewed.

Submitted 29 October 2020; revised 15 January 2021; accepted 18 January 2021.

From the Sparrow-Michigan State University Family Medicine Residency Program, Michigan State University College of Human Medicine, East Lansing (JPP); American Board of Family Medicine, Lexington, KY (ZJM, AWB, LEP); Department of Family and Community Medicine, University of Kentucky, Lexington (ZJM, AWB, LEP).

Funding: None.

Conflict of interest: Drs. Bazemore and Peterson and Mr. Morgan are employees of the American Board of Family Medicine.

Corresponding author: Lars E. Peterson, MD, $\mathrm{PhD}$, American Board of Family Medicine, 1648 McGrathiana Parkway, Suite 550, Lexington, KY 40511-1247, Phone: 859-269-5626, Fax: 859-335-7509 (Email: lpeterson@ theabfm.org).

\section{See Related Article on Page 665.}

We used data from the 2014 through 2019 American Board of Family Medicine (ABFM) Family Medicine Certification Examination registration questionnaires ${ }^{9}$ for graduating FM residents. In each year, examination candidates were asked how much student debt they had. We summarized the proportion in each category by year. We tested for trends within each category of debt using Cochran-Armitage tests. The American Academy of Family Physicians Institutional Review Board approved this study.

Our sample was 20,104 graduating residents, with a response rate of $100 \%$. We found large and significant increases in the proportion of FM residents with a self-reported debt of $\geq \$ 250,000$, with offsetting significant decreases in the proportion of FM graduates with self-reported debt between $\$ 150,000$ and $\$ 249,999$ levels (Figure 1). The proportion of graduates with exceedingly high selfreported debt increased by $81 \%$, from $25.7 \%$ of graduates to $46.5 \%$ of all FM graduates in 5 years.

This increase in such high levels of educational debt is surprising, because the median debt of US allopathic students increased by only $\$ 20,000$ over this period, and the proportion of graduating allopathic students with any debt decreased. ${ }^{1}$ This increase in FM residents' debt may be explained by growth in the proportion of osteopathic graduates; decline in the proportion of non-US-citizen international medical school graduates, who typically have less debt; other unexplained financial pressures on the FM cohort; or other unmeasured demographic shifts. ${ }^{10}$

These increases in residents' debt levels are concerning because they negatively influence the future physician workforce. $^{5-7}$ Previous analyses have 
Figure 1. Student debt of graduating Family Medicine Residents seeking ABFM certification 2014 to 2019, (n = 20,104). *Cochrane-Armitage test for trend significant within the category over time at $P<.05$.

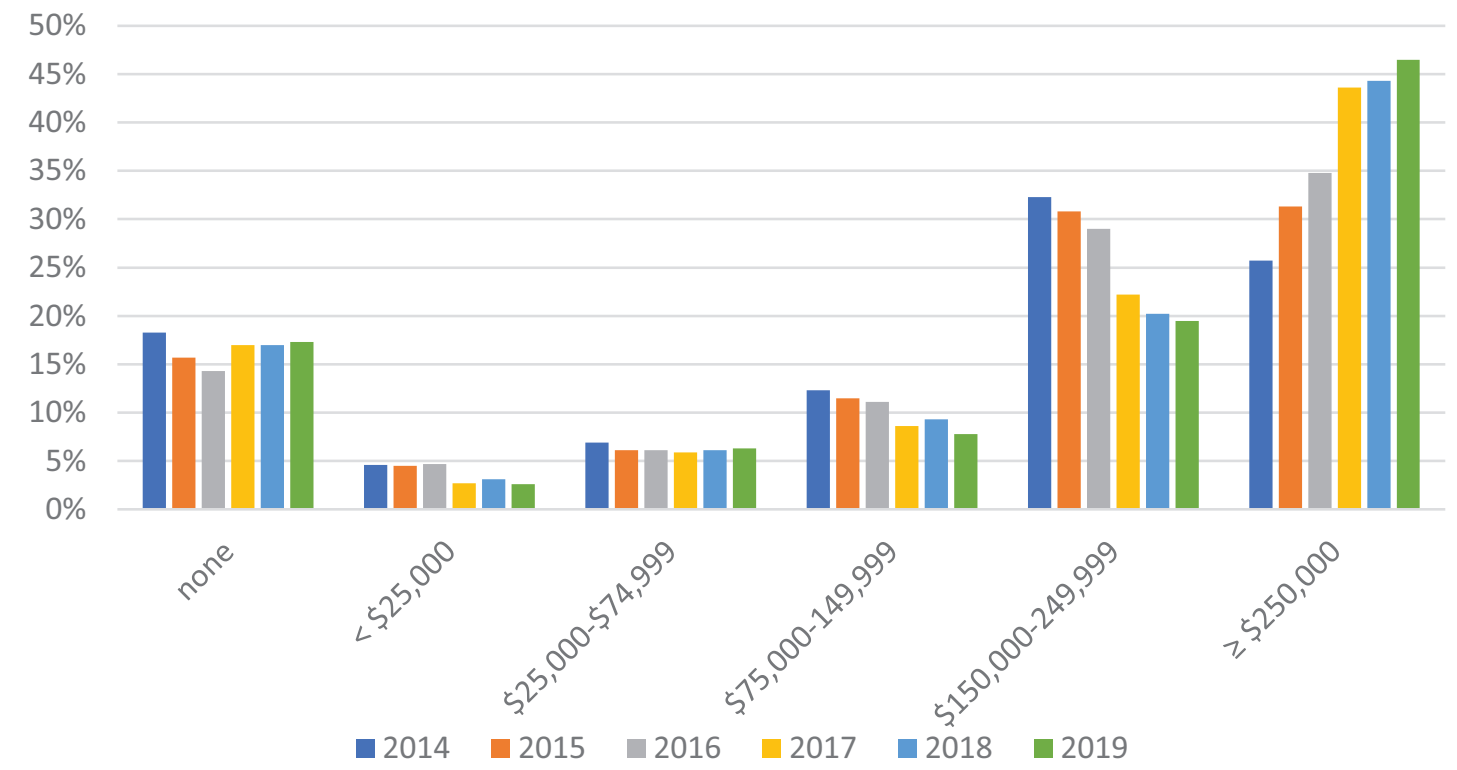

demonstrated that residents with high debt are less likely to choose first jobs in government-owned or subsidized practices, including Federally Qualified Health Centers, rural health clinics, the Indian Health Service, the US Public Health Service, state and local government-operated clinics, and the Department of Veterans Affairs. ${ }^{5}$ Highly indebted graduates are also about one-third as likely to pursue careers in academics and geriatrics, compared with graduates with low debt. ${ }^{5}$ Rapid increases in highly indebted family medicine residents are concerning, meriting further study and attention from researchers and policy-makers.

To see this article online, please go to: http://jabfm.org/content/ 34/3/663.full.

\section{References}

1. Youngclaus JA, Fresne JA. Physician Education Debt and the Cost to Attend Medical School. 2020. Available from: https://www.aamc.org/system/files/ 2020-10/aamc-2020-physician-education-debt.pdf. Accessed October 20, 2020.

2. American Association of Colleges of Osteopathic Medicine. 2018-2019 Academic Year Graduating Seniors Summary Report. 2019. Available from: https:// www.aacom.org/docs/default-source/data-and-trends/ aacom-2018-2019-academic-year-graduating-seniorssurvey-summary-report.pdf?sfvrsn=b5310e97_4.

3. Pisaniello MS, Asahina AT, Bacchi S, et al. Effect of medical student debt on mental health, academic performance and specialty choice: a systematic review. BMJ Open 2019;9:e029980. Accessed April 25, 2021.

4. Phillips JP, Petterson SM, Bazemore AW, Phillips RL. A retrospective analysis of the relationship between medical student debt and primary care practice in the United States. Ann Fam Med 2014;12:542-9.

5. Phillips JP, Peterson LE, Fang B, Kovar-Gough I, Phillips RL., Jr. Debt and the emerging physician workforce: the relationship between educational debt and family medicine residents' practice and fellowship intentions. Acad Med 2019;94:267-73.

6. Phillips JP, Peterson LE, Kovar-Gough I, O’Neill TR, Peabody MR, Phillips RL., Jr. Family medicine residents' debt and certification examination performance. PRiMER 2019;3:7.

7. West CP, Shanafelt TD, Kolars JC. Quality of life, burnout, educational debt, and medical knowledge among internal medicine residents. JAMA 2011;306:952-60.

8. Bazemore A, Peterson L, Jetty A, Wingrove P, Petterson S, Phillips R. Over half of graduating family medicine residents report more than $\$ 150,000$ in educational debt. J Am Board Fam Med 2016;29:180-1.

9. Peterson LE, Fang B, Phillips RL, Jr., Avant R, Puffer JC. The American Board of Family Medicine's data collection method for tracking their specialty. J Am Board Fam Med 2019;32:89-95.

10. Phillips JP, Wendling A, Bentley A, Marsee R, Morley CP. Trends in US medical school contributions to the family physician workforce: 2018 update from the American Academy of Family Physicians. Fam Med 2019;51:241-50. 